\title{
Formulation of a New Generation of Liposomes from Bacterial and Archeal Lipids
}

\author{
Abdulghani Ameri ${ }^{1}$, Eskandar Moghimipour ${ }^{2,3}$, Zahra Ramezani ${ }^{3}$, Mohammad \\ $\mathrm{Kargar}^{4}$, Mahmood Hashemitabar ${ }^{2}$, Sadegh Saremy ${ }^{2}$ and Somayeh Handali ${ }^{3 *}$ \\ ${ }^{1}$ Department of Drug and Food Control, Faculty of Pharmacy, ${ }^{2}$ Cellular and Molecular Research Center, ${ }^{3}$ Nanotechnology \\ Research Center, Jundishapur University of Medical Sciences, Ahvaz, ${ }^{4}$ Department of Microbiology, Jahrom Branch, Islamic \\ Azad University, Jahrom, Iran
}

*For correspondence: Email: handali_s81@yahoo.com

Received: 30 June 2015

Revised accepted: 21 December 2015

\begin{abstract}
Purpose: To evaluate the application of bacterial liposomes and archaeosomes as a novel drug delivery system for in vitro cytoplasmic delivery of molecules into cancer cells.

Methods: Bacterial membrane lipids were extracted using chloroform and methanol. Bacterial liposomes and archaeosomes of E. coli, Acidianus brierleyi and Sulfolobus acidocaldarius were prepared using film method and their trailing in cancer cells (HT-29) was evaluated by carboxyfluorescein (CF). Their morphological characteristics were assessed by atomic force microscopy (AFM).

Results: At $37^{\circ} \mathrm{C}$, the liposomes and archaeosomes interacted with cell membranes predominantly by fusion and endocytosis. The AFM images showed uniform and dispersed distribution of the liposomes.

Conclusion: The findings demonstrate that bacterial liposomes and archaeosomes may be useful as drug delivery carriers for the treatment of cancer.
\end{abstract}

Keywords: Liposome, Archaeosome, E. coli, Acidianus brierleyi, Sulfolobus acidocaldarius, Cancer, HT-29 cell, Atomic force microscopy, Film method

Tropical Journal of Pharmaceutical Research is indexed by Science Citation Index (SciSearch), Scopus, International Pharmaceutical Abstract, Chemical Abstracts, Embase, Index Copernicus, EBSCO, African Index Medicus, JournalSeek, Journal Citation Reports/Science Edition, Directory of Open Access Journals (DOAJ), African Journal Online, Bioline International, Open-J-Gate and Pharmacy Abstracts

\section{INTRODUCTION}

Cancer includes a heterogeneous array of malignant diseases which are characterized by unregulated proliferation of aberrant cells. Despite significant advances in screening and treatments, it is still the second leading cause of mortality. Chemotherapy is one of the common approaches for cancer treatment. However, it lacks selective targeting of proliferating cancer cells and thus both tumor and healthy cells are killed. Nano- carriers have been investigated for enhancing the efficacy and decreasing the side effects of therapeutic agents and many nano- drug delivery systems have been successfully developed for these purposes [1].

Liposomes are spherical vesicles with concentric phospholipid bilayers that can act as biocompatible, biodegradable and nonimmunogenic drug carriers [2]. The advantages of nano-carriers are their ability to entrap both lipophilic and hydrophilic drugs, selective delivery of entrapped drug to the targeted site, protecting encapsulated agents from metabolic processes, improved therapeutic indices, and increased circulation life times of the drug [2]. Despite worldwide interest in therapeutic applications of 
liposomes in biotechnology, their preparation remains as a challenging issue [3]. Liposomes can be prepared from synthetic lipids such as dioleoylphosphatidylcholine or natural phospholipids (egg or soya) [4]. Although these preparations are very useful, they are expensive and commercially available from limited sources worldwide [3].

Several studies have attempted to develop an alternative for synthetic liposomes. One of these approaches is to use bacterial lipid membranes. Although conventional liposomes are unstable, have relatively short half- life and highly expensive to produce on a large scale $[4,5]$, the ease of access to microorganisms throughout the year and their ability to grow on various substrates, make bacterial lipids suitable candidates for liposome preparation [6].

Archaeosomes are a new generation of liposomes that composed of one or more polar ether lipids extracted from Archaea or synthetic archaeal lipids. These microorganisms live under harsh conditions including high temperatures, high salinity, high pressures, and extreme $\mathrm{pH}$ $[7,8]$. The ether linkages are more stable than esters against oxidation and high temperature [9]. Accordingly, archaeosomes are more resistant under such conditions [7-9].

The objective of this study was to explore the use of bacterial liposomes prepared by lipids extracted from Escherichia coli (E. coli) cultures, and archaeosomes made with lipids derived from A. brierleyi and $S$. acidocaldarius as vehicles for cytoplasmic delivery of molecules to cancer cells.

\section{EXPERIMENTAL}

The freeze-dried sealed glass ampoule of $E$. coli (ATCC no. 25922) was obtained from the Iranian Research Organization for Science and Technology (Tehran, Iran). S. acidocaldarius and $A$. brierleyi were kindly donated by National Iranian Copper Industries Co. (Sarcheshmeh, Kerman, Iran). Dulbecco's modified eagle's medium (DMEM) and 5(6)- carboxyfluorescein (CF) were obtained from Sigma-Aldrich (Germany). Fetal bovine serum (FBS) was purchased from Gibco, USA. HT-29 cells were obtained from Pasteur Institute of Iran (ATCC no. HTB-38).

\section{Preparation of liposomes and archaeosomes}

The lipid extraction of $E$. coli and Archaea was performed using $1 / 2$ and $2 / 1(\mathrm{v} / \mathrm{v})$ mixtures of chloroform/methanol, respectively $[3,10]$. Liposomes and archaeosomes were prepared from the extracted lipid by thin film method. Briefly, $2 \%$ CF was added to the extracted lipid solution and mixed. The mixture was evaporated in a rotary evaporator (Heidolph, Germany). When a thin film was formed in a round-bottom flask, it was hydrated with phosphate buffer $(\mathrm{pH}$ 7.4). The suspension was vortexed for $30 \mathrm{~min}$ and then sonicated for $45 \mathrm{~min}$ [11]. Morphology of the samples was assessed by an atomic force microscope (AFM, JPK, Nanowizardz, Germany).

\section{Evaluation of liposome and archaeosome uptake by cancer cells}

HT-29 human colonic epithelial cells were grown at $37{ }^{\circ} \mathrm{C}, 5 \% \mathrm{CO}_{2}$ and $95 \%$ relative humidity in DMEM supplemented with $10 \%$ FBS, $1 \%$ nonessential amino acids, and $1 \%$ penicillinstreptomycin. One $\mathrm{ml}$ of $\mathrm{CF}$ loaded liposomal and archaeosomal suspension was added to 5 $\mathrm{mL}$ of DMEM of which $1 \mathrm{~mL}$ was incubated with a monolayer of HT-29 cells at $37^{\circ} \mathrm{C}$ for different times (15, 60 and $120 \mathrm{~min})$. After incubation, the cells were washed 3 times with PBS and then observed with inverted microscope (Olympus, IX7 Japan) [3].

\section{RESULTS}

AFM images showed distinct and uniform particles (Fig 1) and particle size which were in the range of 35 to $200 \mathrm{~nm}$ (Fig. 2). Bacterial liposomes were able to pass the HT-29 cells within the first $15 \mathrm{~min}$ of incubation at $37^{\circ} \mathrm{C}$; and a decrease in the fluorescence signal is observed after 60 and $120 \mathrm{~min}$. (Fig. 3b). The archaeosomes could enter the cells within 15 and $60 \mathrm{~min}$ where fluorescence signal was clearly observed, whereas after $120 \mathrm{~min}$, fluorescence signal decreased (Fig. 3b-e), The CF-loaded bacterial liposomes and archaeosomes were also incubated for the same times at $4{ }^{\circ} \mathrm{C}$. At this temperature, the interaction of the nanoparticles with cells were very low (Fig. 4).

\section{DISCUSSION}

The present study, we assessed the morphology of vesicles which are composed of bacterial and tetra-ether lipids by AFM images imaging. The AFM technique in the tapping and non-contact mode approaches allows the observation of the liposomal morphology without any sample manipulation such as labeling, staining, or fixation [14]. 

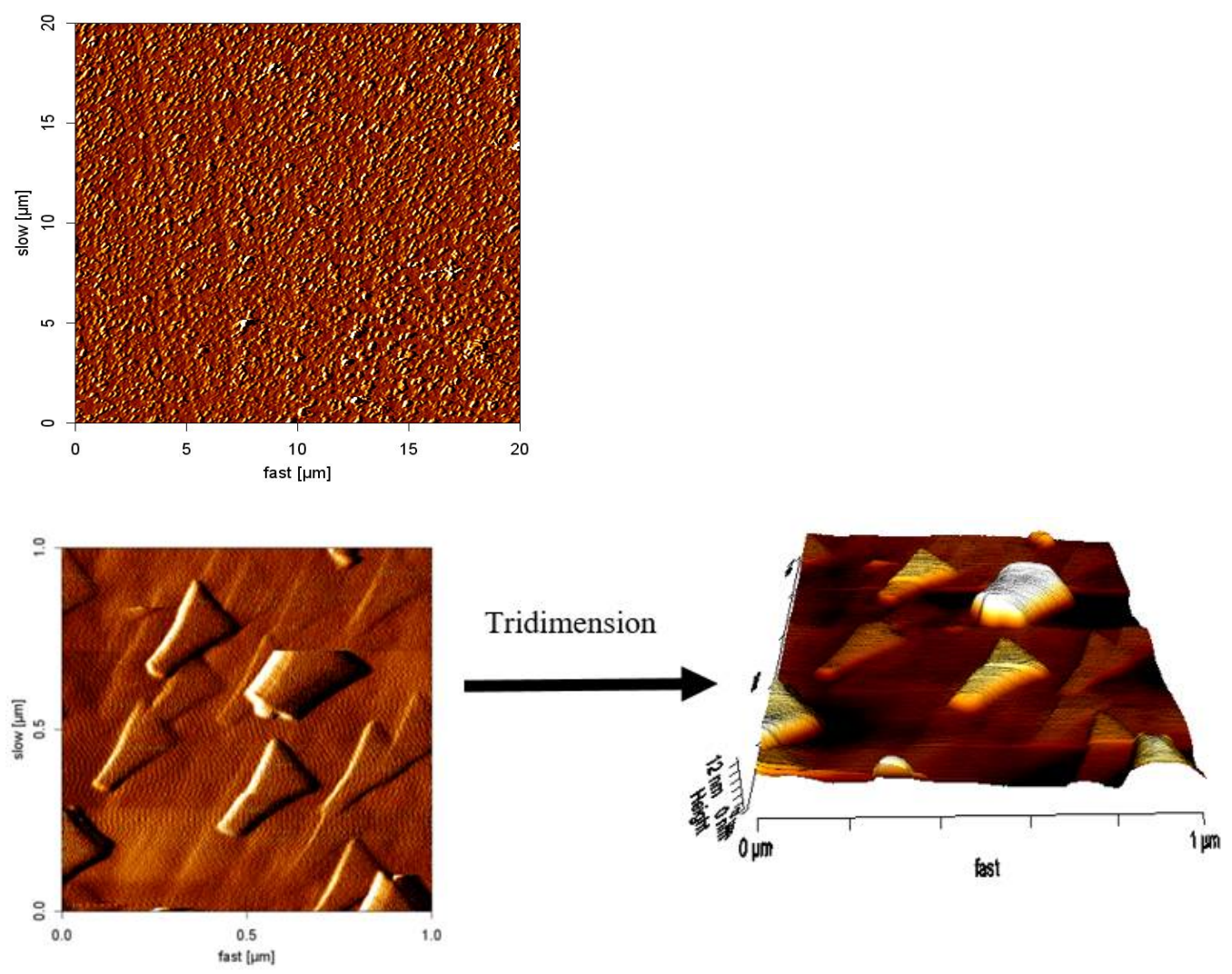

Figure 1: AFM images of liposomes

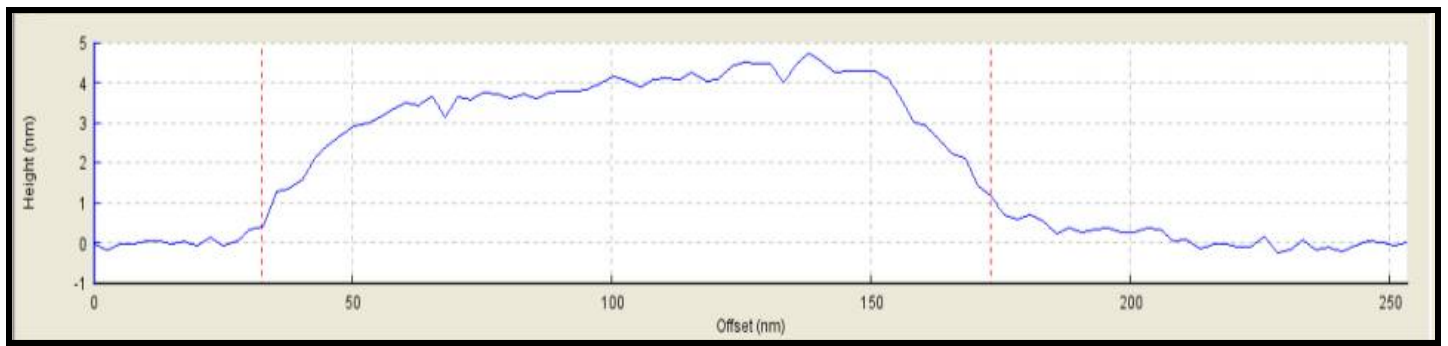

Figure 2: Particle distribution of E. coli-derived liposomes


Figure 3: CF contaning liposomes and archaeosomes incubated with HT-29 cells for different time intervals at $37^{\circ} \mathrm{C}$ : a) Bacterial liposome after $\left.15 \mathrm{~min}, \mathrm{~b}\right)$ Archaeosomes of A.brierleyi after $\left.15 \mathrm{~min}, \mathrm{c}\right)$ Archaeosomes of A.brierleyi after $60 \mathrm{~min}, \mathrm{~d}$ ) Archaeosomes of S.acidocaldarius after $15 \mathrm{~min}$, e) Archaeosomes of S.acidocaldarius after $60 \mathrm{~min}$ 
The AFM images showed distinct uniform particles. It has been previously reported that liposomes can change their shape once deposited on mica and contact motion of the tip (tapping) of AFM eliminates lateral or shear forces which would deform or scrape the sample [14]. The HT-29 cells are suitable alternative models for studying the cell bypass transport pathway [15]. Therefore, they were employed for evolution of ability of bacterial liposomes and archaeosomes in delivery of CF to cancer cell. $\mathrm{CF}$ is a commonly used aqueous dye as fluorescent reporter [3]. The results showed that bacterial liposomes were able to pass the HT-29 cells within the first $15 \mathrm{~min}$ of incubation at $37^{\circ} \mathrm{C}$, after which a decrease in the fluorescence signal was observed after 60 and $120 \mathrm{~min}$. This phenomenon can be attributed to can be attributed to intracellular degradation of the liposomes, after uptake, resulting in dilution of the fluorescent dye, which in turn decreases the fluorescence signal [3]. These results are in agreement with the previous findings of a study where delivery of molecules to cancer cells was assessed by employing E. coli liposomes. They incubated CF-loaded liposomes as a drug model with HeLa cells at different time periods $(15,60$ and $120 \mathrm{~min}$ ) [3]. It was reported that liposomes could uptake cells within the first $15 \mathrm{~min}$ of incubation, followed by a reduction of the fluorescence signal after 60 and $120 \mathrm{~min}$.

It was observed that archaeosomes could enter the cells within 15 and $60 \mathrm{~min}$. as was signaled by a reduction in the fluorescence. However, after 120 min., showed a decrease in fluorescence. The results indicate that archaeosomes were more stable than bacterial liposomes in delivery of CF to cancer cells. The present findings are in agreement with the results of Gonzalez et al that prepared archaeosomes from total polar lipids of Halorubrum tebenquichense and trailed them in $\mathrm{J} 774$ cells (murine macrophages) using a hydrophilic dye pyranine (HPTS: 8-hydroxypyrene-1, 3, 6trisulfonic acid). Their results showed that the archaeosomes did not fuse or disrupt staying inside the phagosomes for at least $60 \mathrm{~min}$ [16]. However, our findings are not in agreement with Higa et al (2012) who evaluated cell uptake of HPTS-containing ultradeformable archaeosomes (UDA); a type of vesicles that made of soybean phosphatidylcholine, sodium cholate, and polar lipids from Halorubrum tebenquichense. The uptake of HPTS-labeled vesicles was followed in J774 cells for $5 \mathrm{~h}$. In this period, J774 cells captured HPTS-UDA following a linear kinetics [17]. It was suggested that it is possible to achieve high stability for a long time drug delivery into cells by adding soybean phosphatidylcholine and sodium cholate during preparation of archaeosomes made from lipid extract of $S$. acidocaldarius and $A$. brierleyi.

The findings suggest that uptake of the nanoparticles following their adsorption on cellular membrane, occurs by endocytosis. At 37 ${ }^{\circ} \mathrm{C}$, liposomes interact with cell membranes. At $37^{\circ} \mathrm{C}$, liposomes interact with cell membranes predominantly by fusion and endocytosis [18]. The CF-loaded bacterial liposomes and archaeosomes were also incubated for the same times at $4{ }^{\circ} \mathrm{C}$. Previous studies have reported negligible or no endocytotic activity in cells at this temperature [3]. These nano-systems are loosely associated with cells at this temperature. The results indicate that uptake of liposomes and archaeosomes by cells at $37^{\circ} \mathrm{C}$ was faster than at $4{ }^{\circ} \mathrm{C}$. These results support the study of Lee et al who studied the delivery of calcein (as a fluorescent dye) containing liposomes into cultured KB Cells (a human nasopharyngeal cancer cell line) via folate receptor-mediated endocytosis. They observed that folateconjugated liposomes are endocytosed only at $37^{\circ} \mathrm{C}$, while, no cytoplasmic fluorescence was observed at $4{ }^{\circ} \mathrm{C}$ [19]. Furthermore, Gurnani et al (2004) reported that uptake of archaeosomes with a net negative surface charge by endocytosis may be mediated via recognition by the phosphatidylserine receptor [20]. Further investigations are needed to determine the exact mechanism of CF uptake.

Liposomes can be formulated from bacterial lipids of E. coli [5]. The cytoplasmic membrane of the $E$. coli includes a high proportion $(70-75 \%)$ of phosphatidylethanolamine [21]. Therefore, it can be considered as suitable candidate for formulation of liposomes. Chauhan et al developed E. coli membrane lipid vesicles (escheriosomes) and demonstrated that escheriosomes successfully fuse with the plasma membrane of macrophages, which leads to effective cytoplasmic delivery of entrapped antigen, a prerequisite for inducing $\mathrm{CD} 8^{+} \mathrm{T}$ cell response against antigens [22]. The findings which are in line with previous reports suggest that phospholipids derived from $E$. coli membrane may be a good candidate for preparation of liposomes or escheriosomes as nano-carriers for both drug deliveries to the cancer cells and as adjuvant for vaccine delivery. Since autoclaving is one of the most effective decontamination methods, therefore, the ability to maintain vesicle integrity after autoclaving would be a desirable property for systemic use of liposomes. One approach for achieving this feature is the use of liposomes that are composed of ether lipids isolated from Archaea. 
$S$. acidocaldarius thrives at temperatures range of $65-85^{\circ} \mathrm{C}$ [23].

In our previous HPTLC analysis, we reported that more than $78 \%$ of the bacterial cell membrane is composed of glycerol ether [13]. Brown et al investigated the stability of liposomes made from the lipid isolated from the thermoacidophilic archaeon $S$. acidocaldarius against autoclaving. According to their findings, archaeosomes were autoclavable as they could retain their size, morphology and most of the entrapped CF [23].

The results of stability assessment showed high consistency with the study of Brown et al for exploring archaeosomes in biotechnological applications as drug delivery system for drugs, genes, or cancer imaging agents. An ideal vector in drug delivery should be highly efficient in delivering the drug in a target-specific manner, stable in vitro as well as in vivo, nontoxic and non-immunogenic [24]. Many in vivo studies involving intravenous, subcutaneous, and oral administration of archaeosomes have demonstrated that archaeosomes are safe molecules and nontoxic [25]. Further studies are needed to modify and improve the characteristics of bacterial liposomes and archaeosomes as drug delivery systems, followed by in vivo studies. Bacterial liposomes are readily disrupted at low $\mathrm{pH}$ in the gastrointestinal tract, thus to overcome this problem of instability, encapsulation of enteric-coated capsules will be investigated in future studies.

\section{CONCLUSION}

Bacterial liposomes and archaeosomes can enhance drug delivery to cancer cells. Our findings showed higher efficacy of archaeosomes, compared with bacterial liposomes in delivering molecules through cancer cells. These lipid vesicles may be internalized by endocytotic pathways. Intracellular uptake is the main permeation mechanism and biodegradation of the liposomes and archaeosomes inside the cancer cells has been demonstrated.

\section{ACKNOWLEDGEMENT}

The work was financially supported by Nanotechnology Research Center, Ahvaz Jundishapur University of Medical Sciences, Ahvaz, Iran (grant No. 57). The authors gratefully thank National Iranian Copper Industries Co. (Sarcheshmeh, Kerman, Iran) for kindly providing A. brierleyi and S. acidocaldarius.

\section{REFERENCES}

1. Krishnamachari $Y$, Geary SM, Lemke $C D$, Salem $A K$. Nanoparticle delivery systems in cancer vaccines. Pharm Res 2011; 28: 215-236.

2. Sun $W$, Zhang $N$, Li A, Zou W, Xu W. Preparation and evaluation of N3-O-toluyl-fluorouracil-loaded liposomes. Int J Pharmaceut 2008; 353: 243-250

3. Gupta V, Gupta R, Grover R, Khanna R, Jangra V, Mittal A. Delivery of molecules to cancer cells using liposomes from bacterial culture. J Nanosci Nanotech 2008; 8: 2328-2333.

4. Moghimipour E, Handali S. Liposomes as drug delivery systems: properties and applications. RJPBCS 2013; 4: 169-185.

5. Barbeau J, Cammas Marion S, Auvray P, Benvegnu T. Preparation and characterization of stealth archaeosomes based on synthetic PEGylated archael tetraether lipid. J Drug Del 2011; 2011: 1-11.

6. Kargar M, Moghimipour E, Ramezani Z, Handali S. Application Potential of Liposomal Delivery Systems Prepared by Lipids Extracted from E.coli Culture. Annu Res Rev Biol 2014; 4: 1319-1329.

7. Benvegnu T, Lemiegre L, Cammas-Marion S. Archaeal lipids: innovative material for biotechnology applications. Eur. J Org. Chem 2008; 4725-4744.

8. Van de Vossenbreg JLCM, Driessen AJM, Konings WN. The essence of being extermophilic: the role of the unique archaeal membrane lipids. Extremophiles 1998; 2: 163-170.

9. Langworthy TA. Comparative lipid composition of heterrophically and autotrohyically grown Sulfolobus acidocaldarius. J Bacteriol 1977; 130: 1326-1332.

10. Moghimipour E, Handali S. Utilization of thin film method for preparation of celecoxib loaded liposomes. Adv Pharmaceut Bull 2012; 2: 93-98.

11. Moghimipour E, Kargar M, Ramezani Z, Handali S. Archaeosome Made from Lipids Extracted of Acidianus brierleyi as an Innovative Drug Delivery System. J Pure Appl Microbiol 2014; 8: 957-964.

12. Moghimipour E, Kargar M, Ramezani Z, Handali S. The potent in vitro skin permeation of archaeosome made from lipids extracted of Sulfolobus acidocaldarius. Archaea 2013; 2013: 1-7.

13. Ruozi B, Belletti D, Tombesi A, Tosi G. Bondioli L, Forni $F$, Vandelli MA. AFM, ESEM, TEM, and CLSM in liposomal characterization: a comparative study. Int $\mathrm{J}$ Nanomed 2011; 6: 557-563.

14. Lee MKK, Dilq. Drug development in cell culture: crosstalk from the industrial prospects. I Bioequiv Availab 2014; 6: 96-114.

15. Gonzalez RO, Higa HL, Cutrullis RA, Bilen M, Morelli I, Roncaglia DI, Corral RS, Morilla MJ, Petray PB, Romero EL. Archaeosome made of Halorubrum tebenquichense total polar lipids: a new source of adjuvancy. BMC Biotechnol 2009; 9: 1-12.

16. Higa $L H$, Schilrreff $P$, Perez $A P$, Iriarte $M A$. Ultradeformable archaeosomes as new topical

Trop J Pharm Res, February 2016; 15(2): 219 
adjuvants. Nanomedicine: Nanotechnol Biol Med 2012; 8: 1319-1328.

17. Holovati JL, Gyongyossy-Issa MIC, Acker JP. Effect of liposome charge and composition on the delivery of trehalose into red blood cells. Cell Preserv Technol 2008; (6) 207-218.

18. Lee RJ, Low PS. Delivery of liposomes into cultured KB cells via folate receptor-mediated endocytosis. The $J$ of Biological Chem 1994; (269): 3198-3204.

19. Gurnani K, Kennedy J, Sad S, Sprott GD, Krishnan L. Phosphatidylserine receptor-mediated recognition of archaeosome adjuvant promotes endocytosis and MHC class I cross-presentation of the entrapped antigen by phagosome-tocytosol transport and classical processing. J Immunol 2004; (173): 566-578.

20. White GF, Racher KI, Andre L, Hallett FR, Wood JM. Physical properties of liposomes and proteoliposomes prepared from Escherichia coli polar lipids. Biochimica et Biophysica Acta 2000; (1468): 175-186.
21. Chauhan A, Swaleha Z, Ahmad N, Farazuddin $M$, Vasco A, Abida M, Mohammad O. Escheriosome mediated cytosolic delivery of Candida albicans cytosolic proteins induces enhanced cytotoxic $T$ lymphocyte response and protective immunity. Vaccine 2011; (29): 5424-5433.

22. Browna DA, Venegas B, Cooke PH, English V, Lee-Gau Chong $P$. Bipolar tetraether archaeosomes exhibit unusual stability against autoclaving as studied by dynamic light scattering and electron microscopy. Chem Phys Lipid 2009; (159): 95-103.

23. Poklar Ulrih N, Gmajner D, Raspor P. Structural and physicochemical properties of polar lipids from thermophilic archaea. Appl Microbiol Biotechnol 2009; (84): 249-260.

24. Alqueres SMC, Almeida RV, Clementino MM, Vieira RP, Almeida WI, Cardoso AM, Martins O. Exploring the biotechnological application in the archaeal domain. Brazilian J Microbiol 2007; (38): 398-405. 